White Paper on the Proposed Design, Development, and Implementation of a Monitored Retrievable Storage Module and the Siting Criteria for Spent Nuclear Fuel

Bob Villarreal

Dan Knobeloch 



\section{DISCLAMMER}

Portions of this document may be illegible in electronic image products. Images are produced from the best avallable original document. 

ABSTRACT 1

EXECUTIVE SUMMARY 1

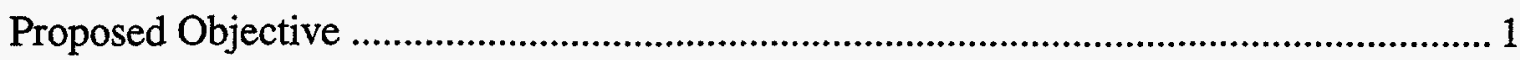

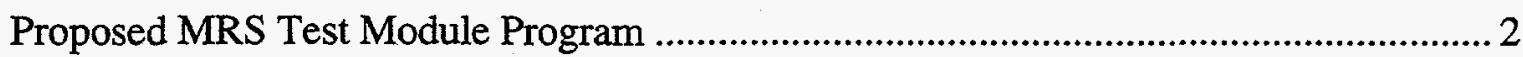

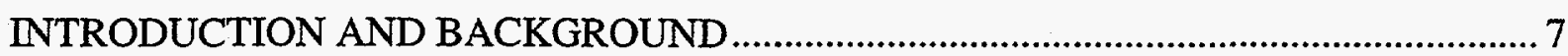

THE CIVILIAN RADIOACTIVE WASTE MANAGEMENT SYSTEM PLAN …................. 7



The Federal Repository ..............................................................................................

LOS ALAMOS ROLE IN THE DEVELOPMENT OF AN MRS MODULE …….................9

MRS TECHNOLOGY CONSIDERATIONS AND THE NEEDS

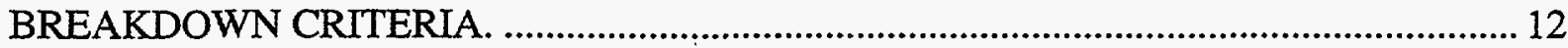

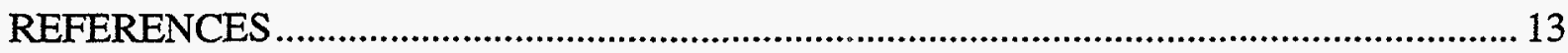

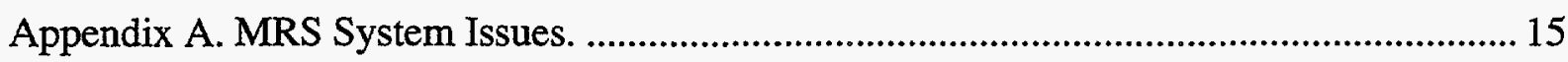

Appendix B. Application of Inert Gas Analysis for Detecting and Monitoring the Integrity of Spent Fuel.

Appendix C. Factors for the Assessment of Technology Development for MRS Projects.

\section{List of Figures}

Chart 1. Systematic Approach to Development of a Monitored Retrievable Storage Site for Spent Nuclear Fuel-Areas of LANL Collaborations.

Figure 1. Prototype MRS Removable/Replaceable Canister and

Vertical Emplacement Module. 


\title{
WHITE PAPER ON THE PROPOSED DESIGN, DEVELOPMENT, AND IMPLEMENTATION OF A MONITORED RETRIEVABLE STORAGE MODULE AND SITING CRITERIA FOR SPENT NUCLEAR FUEL
}

\author{
by
}

Bob Villarreal and Dan Knobeloch

\begin{abstract}
Congress enacted the Nuclear Waste Policy (NWP) Act in 1982 as comprehensive legislation for the DOE to locate, build, and operate repositories to permanently dispose of spent nuclear fuel and other high-level wastes. In 1987, Congress amended the NWP Act and authorized the DOE to site, construct, and operate one Monitored Retrievable Storage (MRS) facility. The MRS facility was planned as a means to enhance the flexibility and reliability of the overall waste management system. This white paper presents a broad prospectus of the scientific and regulatory capabilities at Los Alamos National Laboratory and outlines the methodology to design and implement an MRS test module. This proposed module will incorporate the flexibility to store all types of spent nuclear fuel above or below ground level and will be fully monitored for the residence time of the spent fuel in the MRS module. The purpose of this test module is to define the parameters necessary to build a simple and economical MRS system. Demonstration of the proposed MRS test module will be important because it will form the basis for an integrated MRS site model.
\end{abstract}

\section{EXECUTIVE SUMMARY}

\section{Proposed Objective}

In 1976, a federal program was established to study ways to safely dispose of nuclear waste. Congress enacted the Nuclear Waste Policy (NWP) Act in 1982 as comprehensive legislation for the DOE to locate, build, and operate repositories to permanently dispose of spent nuclear fuel and other high-level wastes. In 1987, Congress amended the NWP Act and authorized the DOE to site, construct, and operate one Monitored Retrievable Storage (MRS) facility. The MRS facility was planned as a means to enhance the flexibility and reliability of the overall waste management system.

The objective of this white paper is to present to the Department of Energy (DOE) a broad prospectus of scientific and regulatory capabilities at Los Alamos National Laboratory (LANL) and outlines the methodology to design and implement an MRS test module. The 
purpose of this test module is to define the parameters necessary to build a straightforward and economical MRS system (see Appendix A). Demonstration of the proposed MRS module is important because the success of the test module will become the basis for an integrated MRS site model (see Figure 1). In this report, we define the technical criteria that impact the development, design, and implementation of an MRS test system. We outline a systematic approach to the development of an MRS site, and we propose the development, testing, and implementation-through use of innovative technology-a robust and dynamically flexible MRS test module. We also outline a comprehensive work breakdown structure which allows specific identification of technical, regulatory, and assessment capabilities that could be effectively applied to guide the development of an MRS system (see Chart 1).

\section{Proposed MRS Test Module Program}

The proposed MRS test module will incorporate the flexibility to store all types of spent nuclear fuel above or below ground level, and each module will be independently operated (i.e., each will be capable of having a different atmosphere), will be fully and continuously monitored, and can be constructed in a short time-frame. The MRS system will use nondestructive monitoring techniques, which are effective for routine monitoring of stored spent fuel to establish its heat content and burnup. To ensure that the MRS remains uncontaminated, the monitoring requirements for this system will be extensive. In addition, the system will use new technologies to analyze inert gas spikes and stable fission gas isotopes to monitor the integrity of spent fuel cladding, the storage facility, and waste containers for many decades (see Appendix B).

The MRS module design incorporates eight major thrusts:

(1) radiation shielding and protection for workers;

(2) corrosion retardation;

(3) elimination of concrete irradiation and subsequent decontamination and decommissioning;

(4) removable/replaceable engineered clay radionuclide absorption barrier;

(5) removable/replaceable primary containment canister;

(6) design standardization for compliance to NRC and DOE criteria;

(7) capability for spent fuel-assembly examination; and

(8) comprehensive monitoring capabilities during the storage life of spent nuclear fuel. This includes inert gas analysis in the parts-per-billion range and measurement of fuel burnup (see Appendix B). 
The capabilities to implement all of the above major thrusts already exist at LANL. These capabilities will be incorporated in the overall MRS test module based on technology assessment factors (see Appendix C).

A successful MRS test module program would also build on the knowledge gained through other existing programs, including (1) the Independent Spent Fuel Storage Installations (ISFSIs) that have been implemented by commercial reactor utilities and have been approved and regulated by the Nuclear Regulatory Commission (NRC) and (2) the expertise based on studies being conducted by LANL at both Yucca Mountain and the Waste Isolation Pilot Plant (WIPP). 


\title{
Chart 1. Systematic Approach to Development of a Monitored Retrievable Storage Site for Spent Nuclear Fuel
}

\author{
Areas of LANL Collaborations
}

\section{Project Goal}

To design, develop, and demonstrate a versatile MRS module prototype with applicability for expansion to MRS site, including technical support structures according to NRC criteria.

Define Scope of Project

1. Independent spent fuel storage installation

2. MRS

Establish Inventory and Location of Spent Nuclear Fuels

1. Stable, fully clad S.S.

2. Stable, fully clad Al

3. Stable, fully clad $\mathrm{Zr}$

4. Semistable, unclad fuel

5. Special fuel types

6. High-level waste form

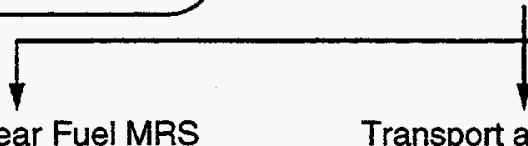

Spent Nuclear Fuel MRS Module Project
Define Spent Nuclear Fuel Types and History of Each Type

Transport and Receipt of Spent Nuclear Fuel Project<smiles>[3H][CH]C</smiles>

Assign Project Leaders



a. Project decision parameters

b. NRC/DOE tech requirements DQOs (10 CFR-72)

c. Project test plan

d. Project management plan

1. U-based fuels

2. U-Pu based fuels

3. $\mathrm{UO}_{2}$ fuel

4. $\mathrm{PuO}_{2}$ fuel

5. Mixed-oxide fuel

6. Special fuels
1. Quantity of fuel

2. Stability limitations

3. Processing necessities

4. Criticality safety

5. ALARA

6. Transport casks

7. Transportation

8. Margins of safety

9. SAR

10. Design criteria

11. Materials science

1. High B.U. $(>10 \%)$

2. Low B.U.

3. Aged $>1$ year

4. Aged $>5$ years

End-Use Options<smiles>[3H][3H]</smiles>

a. Reusable

b. Transmutable

c. Reusable after processing

d. Permanent disposal

(continued) 


\title{
Areas of LANL Collaborations (cont)
}

\author{
Segregation According to End Use \\ $\downarrow$ \\ Establish Regulatory Compliance Requirements
}
a. Permitting
b. Transport casks
c. ISFSI or MRS
d. 10 CFR 72
e. SAR
f. DOE/NRC

Establish and Implement Quality Assurance<smiles>[3H][3H]</smiles>

Design MRS Module Prototype with Replaceable Canister
a. Integrate risk assessments
b. Integrate probabilistic risks
c. Incorporate safety assessments
d. Establish consequence of analysis accidents

\section{Evaluate Design Criteria and Concept} (see MAS module figure)

a. Control radiation exposure (ALARA)

b. Criticality considerations c. Long-term monitoring capability

d. Adaptability

Fabricate Prototype MRS Module

a. Incorporate NRC/DOE criteria

\section{Test MRS Prototype}

a. Replacement canister

b. Radiation shielding

c. Monitoring capabilities

d. Alternate shielding materials

Conduct Performance Assessment

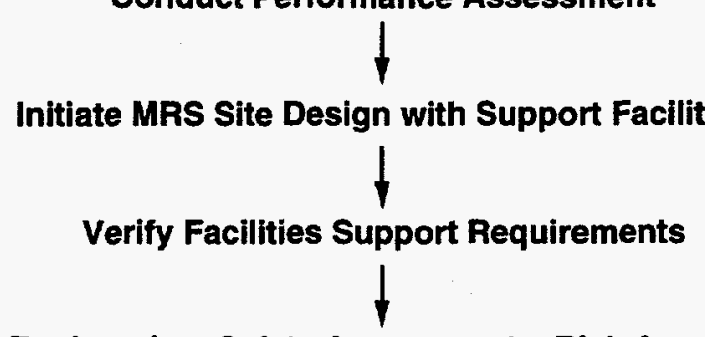

Establish Regulatory, Engineering, Safety Assessments, Risk Assessments for MRS Module<smiles>[3H][3H]</smiles>

Review Adequacy of Structures (10 CFR 72) and Initiate Safety Analysis Report

a. Waste cask-canister design

b. Transportation

c. Receipt, handling, packaging

d. Storage

e. Examination, re-examination capabilities

f. Materials science integration

Develop MRS Site Blueprint

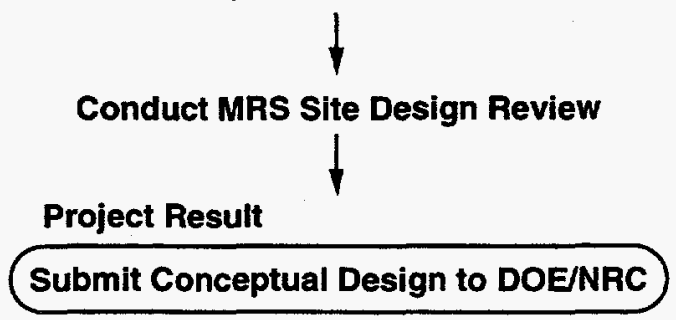




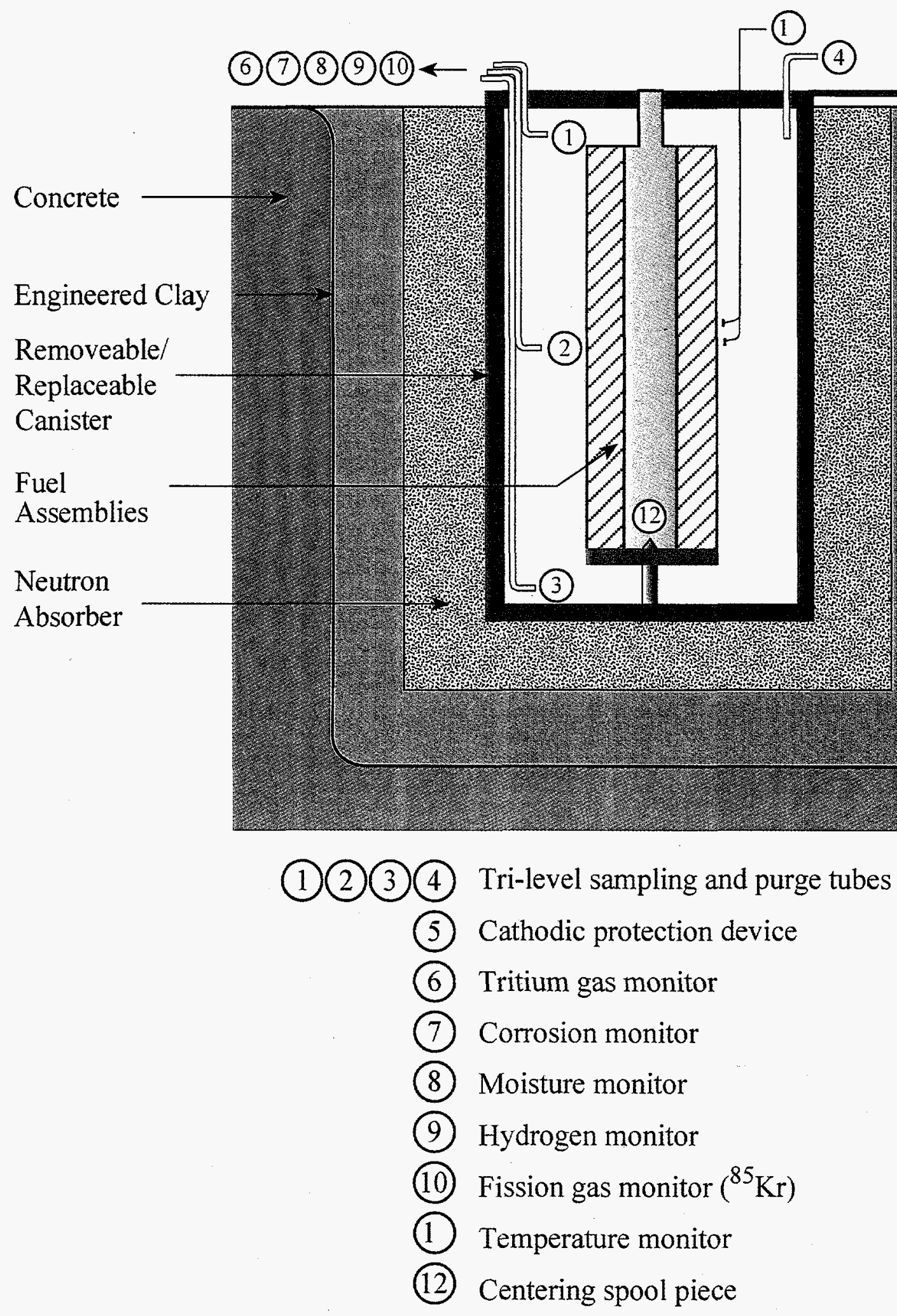

CST-95-553A

(5) Cathodic protection device

6) Tritium gas monitor

(7) Corrosion monitor

Moisture monitor

Hydrogen monitor

Fission gas monitor $\left({ }^{85} \mathrm{Kr}\right)$

(1) Temperature monitor

Centering spool piece

Figure 1. Prototype MRS Removable/Replaceable Canister and Vertical Emplacement Module. 


\section{INTRODUCTION AND BACKGROUND}

In 1976, a federal program was established to study ways to safely dispose of nuclear waste. As a result, Congress enacted the Nuclear Waste Policy (NWP) Act in 1982 as comprehensive legislation for the DOE to locate, build, and operate an underground geologic repository to permanently dispose of spent nuclear fuel and other high-level wastes. To fund the program, Congress established the Nuclear Waste Fund in which electricity produced by commercial nuclear power was taxed to pay for spent fuel storage and disposal. In 1987, Congress amended the NWP Act and directed the DOE to study only one site for a permanent repository. The Yucca Mountain site was selected as the final candidate. In addition, the amendment also authorized the DOE to site, construct, and operate one MRS facility. The MRS facility was planned as a means to enhance the flexibility and reliability of the overall waste management system. The MRS differs from the permanent repository planned for Yucca Mountain in that it is an above-ground facility that will store a limited amount of spent fuel for a limited time.

In response to the 1987 amendments, the NRC established regulations (Title 10, Part 72 of the Code of Federal Regulations) governing the siting, construction, operation, and decommissioning of an MRS. Congress also enacted legislation that established the framework for the Civilian Radioactive Waste Management System (CRWMS), a federal program responsible for the disposition of spent nuclear fuel. From the basic framework of the CRWMS, Congress first established the Office of Civilian Radioactive Waste Management (OCRWM) as well as an independent Office of Nuclear Waste Negotiator (ONWN). The OCRWM oversees many different activities, including the Yucca Mountain study. The ONWN is responsible for developing an agreement between a willing state or Indian tribe and the federal government concerning the terms and conditions for locating the MRS within the state or tribal lands. The proposed agreement and the results of an environmental assessment must be approved by Congress before becoming effective. Financial resources in the Nuclear Waste Fund will be used to cover the benefits offered to the host of the MRS and the costs of decommissioning and dismantling the facility.

\section{THE CIVILIAN RADIOACTIVE WASTE MANAGEMENT SYSTEM PLAN}

The current approach to solving the spent fuel storage and disposal issues includes addressing many regulatory variations that exist between DOE and NRC waste policies. In addition, the nuclear waste inventory is diverse, and new strategies will be necessary to address changes in materials requiring storage or disposal. 
Several ongoing DOE programs are focused on the storage of high-level wastes, which include spent fuel from commercial nuclear reactors; wastes (planned for vitrification in the glass form) from past defense-related material production; enriched fuels from naval and university reactors; fuels from DOE production reactors; wastes from DOE remediation sites; and surplus weapons-capable materials (weapons-grade plutonium and uranium). ${ }^{1}$ Most of these materials are destined for direct geologic disposal, as specified in the NWP Act of 1982 and later amendments. Sites currently under study and/or evaluation for geologic disposal include the WIPP facility and Yucca Mountain.

To facilitate the process by which spent fuel from commercial reactors would be managed under the NWP Act, the OCRWM branch of the DOE initiated the CRWMS. The mission of this system, which will be implemented nationwide, is to store and dispose of all commercial spent reactor fuel. The CRWMS is made up of three parts: (1) an MRS facility, (2) a federal repository, and (3) a transportation system to move spent fuel and high-level wastes to the MRS facility and the permanent repository. All three parts of the program must comply with 10 CFR 72 regulations. Current plans state that the Nuclear Waste Fund will be the primary source of funding for the CRWMS.

\section{The MRS Facility}

The MRS facility will be designed to temporarily store spent fuel and high-level waste until it is shipped to a permanent repository. The MRS will be built above-ground on a site of approximately 500 acres and will be licensed to operate for 40 years. ${ }^{2}$ It will accommodate many different types of shipping containers and will have to be monitored continuously. The shipping canister system will become one of the key design criteria for an MRS module. Currently, several different transport cask designs have been approved by the NRC. At the end of its designed lifetime, the MRS will be decommissioned, and the site will be restored for unrestricted use.

The OCRWM has recognized that the NWP Act deadline of 1998 may not be met in time to address the storage needs for commercial spent fuel. Consequently, many nuclear utilities are planning, or have already implemented, the installation of Independent Spent Fuel Storage Installations (ISFSIs). Approval for the operation of an ISFSI is obtained from the NRC and regulated (via 10 CFR 72) in a similar manner as an MRS. However, an MRS and an ISFSI are not handled identically under this regulation. An ISFSI can be licensed under either of two procedures, a specific license or a general license. The general license does not apply to a MRS. In order to obtain a specific license, a utility must develop a license application that includes designs for the storage hardware, which is usually developed by a 
cask vendor. These issues can be addressed in a Safety Analysis Report (SAR) for both the storage hardware and the civilian facilities. The specific license also involves the preparation and review of environmental impact documentation by the applicant and the NRC. This license can be used at a reactor site or some other location. Considerable time can be involved in processing a specific license because of the public review criteria for the SAR and environmental hearings.

\section{The Federal Repository}

The permanent disposal facility will be an underground repository designed to demonstrate containment of high-level radioactive material for up to 10,000 years. The facility will include above-ground facilities to handle and monitor the wastes and "engineered barriers" below ground for final storage. Site characterization studies at Yucca Mountain will consist of geologic, hydrologic, seismologic, and other tests to verify site stability and containment of the radioactive wastes. OCRWM has final oversight of the permanent storage facility.

\section{LOS ALAMOS ROLE IN THE DEVELOPMENT OF AN MRS MODULE}

The MRS system outlined in this report will address the storage of many different spent fuel and high-level waste materials. Currently, there are 109 operating commercial nuclear plants in the United States that provide approximately $18 \%$ of our total electrical energy. The DOE has 50 facilities that will require the use of an MRS system for storage of spent fuel, including materials from Idaho National Engineering Laboratory, Savannah River Plant, and the Hanford Reservation, and propulsion fuel from the US Navy. ${ }^{1}$ In the commercial arena, 15-20 plants are likely to be shut down over the next ten years because of the decreased use of nuclear energy for production of electrical power.

Current estimates for spent fuel storage capacity for 1990 were 53,300 metric tons. This capacity will increase to approximately 58,700 metric tons in 1995 . However, with the anticipated shutdown schedule for both commercial and DOE facilities, this figure will rise by approximately 1,900 metric tons per year through the year 2000 . From these figures, it is clear that the generation rate of high-level radioactive waste will continue for at least another five to six years. ${ }^{3}$ Therefore, an MRS system, or the related ISFSIs, will be required in the near future in order for the DOE to meet legal obligations outlined in the NWP Act and later amendments. Six ISFSIs have been licensed to operate by the NRC. Another three ISFSIs are 
near approval or have already started operation. Therefore, technology needs for dry storage have been primarily driven by industry.

The DOE and, specifically, Los Alamos can play an important role in the development and implementation of state-of-the-art technologies to support the construction of a safe and reliable MRS system. In this report, we propose that an effective means to demonstrate storage technology improvements extending beyond the capabilities currently planned or implemented in the ISFSIs would be the fabrication, testing, and implementation of a prototype MRS module incorporating advanced technologies and inherent simplicity as outlined in Figure 1. This prototypical MRS module is designed to incorporate

- simplicity of construction and operation;

- an economical alternative because of simplicity and design standardization;

- the flexibility to store all types and configurations of spent nuclear fuels;

- the capability to provide a unique atmosphere (air, inert gas, dry air) for each module;

- the capability to automatically and continuously monitor each module for each fuel type; and

- constructability of each module and an entire MRS site complex in a short time-frame. Demonstration of the proposed MRS module is important because it will be the basis for configuration of the overall MRS complex.

The prototype MRS module design shown in Figure 1 illustrates the eight major thrusts that must be incorporated in an MRS system used for long-term operation. These eight thrusts are as follows:

(1) effective radiation shielding and protection for workers;

(2) corrosion monitoring and retardation capabilities;

(3) neutron absorber barrier for elimination of concrete irradiation by neutron-induced reactions, thereby eliminating subsequent decontamination and decommissioning of the concrete;

(4) removable/replaceable engineered clay radionuclide absorption barrier;

(5) removable/replaceable primary containment canister;

(6) design standardization for compliance to NRC and DOE criteria;

(7) capability for spent fuel-assembly examination, re-examination, and inspection; and

(8) comprehensive monitoring capabilities during the storage life of spent nuclear fuel. This includes inert gas analysis in the parts-per-billion range and measurement of fuel burnup (see Appendix B).

Other technologies could be incorporated into the MRS module design to provide in-place, nondestructive estimates of the burnup of spent fuel. These nondestructive techniques would include (1) a total-profile gamma-ray analysis or total decay heat measurements and (2) 
measurement of burnup by iterative analysis of stable xenon and krypton fission gas ratios (i.e., measuring burnup in unclad fuel wafers or cermets). These techniques could be conducted after the spent fuel has been placed in the MRS module in order to meet characterization requirements or to establish minimum cooling requirements. Invasive measurement techniques could also be used if a more accurate burnup measurement is required (1) before the transfer of spent fuel to a permanent repository, (2) for nuclear material accountability, or (3) for inventory assessments. Invasive measurements would be accomplished by using a laser puncturing device to release and measure the ratio of stable xenon and krypton fission gases generated during irradiation and retained by the spent fuel. In addition, laser ablation techniques could be used to vaporize small quantities (micrograms) of fissile fuel material; the emission signal would then be transmitted to a remotely located high-resolution monochronometer that would measure the fissile isotopes. Typically, these isotopes would include uranium-236, plutonium-240, and neptunium-237. Burnup measurements could be made using uranium-234, uranium-238, or plutonium-239, depending on the original fuel matrix. Any laser-based intrusion of the fuel-cladding material could be resealed by using a defocused laser beam to weld the small hole closed.

All of these technical considerations relate directly to ongoing work and established capabilities at Los Alamos. These considerations are important criteria for the design of a dynamic and integrated system for establishing the properties and characteristics of nuclear waste. A systematic approach to developing an MRS test module, and eventual siting of this system, is proposed to incorporate the above-mentioned technical considerations (see Chart 1). This plan combines the need to merge technical goals with regulatory and quality assurance factors. In addition, technology-driven improvements will be assessed according to factors that address technical maturity, flexibility, and complexity (see Appendix B).

The final deliverable gained from the use of the proposed systematic approach to MRS technology will be a conceptual design and site blueprint. After these plans are accepted by an independent MRS Design Review Committee, they would be ready to submit as a conceptual design to both the DOE and NRC. This approach, which incorporates the fabrication of a prototype MRS module, would offer a flexible and robust MRS system. The MRS module could be developed and implemented in a short time-frame and with the economy of standardization. This capability would serve future needs for the safe and responsible management of spent nuclear fuel and other high-level wastes. 


\section{MRS TECHNOLOGY CONSIDERATIONS AND THE NEEDS BREAKDOWN CRITERIA}

As stated previously, an MRS system will require a license from the NRC pursuant to 10 CFR 72. In order to obtain a license, an application must be developed that includes designs for the storage hardware and the remaining portions of the MRS. Most importantly, the storage hardware is usually developed by the cask vendor. Of the six Independent Spent Fuel Storage Installations licensed to operate, three use the Nutech Horizontal Monitored Storage (NUHOMS) system (24P, 52B) designed by Vectra Technologies for modular dry storage of spent fuel assemblies. Of the six facilities currently in the licensing process, four plan to use the NUHOMS system. Therefore, the preliminary design considerations for a prototype MRS will need to include the NUHOMS storage criteria.

Another important criteria for a standard MRS system will be to determine if the facility will handle "hot" fuel or if the high-level waste will be delivered uncontaminated and remain in that state during the storage lifetime. If fuel consolidation is considered, then facilities must be designed to remotely manipulate highly radioactive fuel elements for packaging into new containers. The trade-off in expense for remote-handling capability versus space consolidation from fuel repackaging must be evaluated. The current plans for an MRS show that it will be constructed to receive "cold" storage casks, which will remain in that state throughout the storage lifetime. To ensure that the MRS remains uncontaminated, the monitoring requirements for this system will be extensive.

Finally, the current plan for an MRS system will probably be driven by the design criteria currently outlined by the DOE. This is because there are no other plans currently in progress by the DOE to implement the single MRS system in accordance with the Nuclear Waste Act and amendments. Los Alamos National Laboratory has been specifically invited to respond to a Technical Needs Breakdown statement outlined by representatives from the participating utilities. Los Alamos was requested to submit a proposal responding to the technical needs because of the diversity of technical capabilities that exist at the Laboratory. A compilation of the Technical Needs Breakdown statement and a response from Los Alamos to these needs are provided in the appendices. 


\section{REFERENCES}

1. US Department of Energy, Spent Fuel Working Group Report on Inventory and Storage of the Department's Spent Nuclear Fuel and other Reactor Irradiated Nuclear Materials and Their Environmental, Safety and Health Vulnerabilities, Volume 1 (US Department of Energy, Washington, D.C., November 1993).

2. VECTRA Fuel Services, "NUHOMS Dry Spent Fuel Management System Planning Guide," VECTRA Fuel Services report MKT94-01J.

3. Turinsky, P.J., S. Baron, W.D. Burch, et al., "West European Nuclear Power Generation Research and Development," Foreign Applied Sciences Assessment Center technical assessment report (September 1991). 


\section{Appendix A. MRS System Issues.}

The following is an identification of needs for an MRS-type fuel storage system for which specific expertise resides at Los Alamos National Laboratory. These issues are of general interest and benefit to the DOE and the industry and are key elements in the development of a system for the effective management of spent nuclear fuel, a current national problem.

\section{REPOSITORY ACCEPTANCE REQUIREMENTS}

\section{A. Liaison with Yucca Mountain Design Team}

Issue. Currently, the information available to the designers of storage and transportation systems for spent nuclear fuel, as regards the repository interface requirements for ultimate disposal, is very limited. The current status and thinking on issues such as heat load limits, heat removal capacity, long-term nuclear criticality control, containment function, and materials for the disposal system design are of key importance to the current design efforts for storage and transport systems. However, gathering this type of data has required reopening the storage and transport canisters, rehandling and repackaging the fuel, and disposing of the old storage and transport canisters. Therefore, better techniques are required to provide as much information as possible to the designers of storage and transport systems.

Action. Through its current role and involvement in the Yucca Mountain project, Los Alamos is in an excellent position to act as a catalyst and liaison for an interactive dialog between the storage and transportation systems design teams and the disposal system design teams. Since the storage and transportation systems design and deployment effort is well ahead of the disposal system, time is of the essence to avoid building in future problems or limitations to the current design efforts.

Benefits. The utilities will benefit through a collaboration and infusion of knowledge in the storage and transport system designs with the avoidance of future rework and unnecessary cost. The DOE will benefit by positively influencing the integrated system design process and delivering, to the nation, a prudent and cost-effective system for the management of spent fuel

Los Alamos Response. As noted in the "Action" portion of this issue, Los Alamos is well prepared to address the interface between transportation activities and storage facilities. Los Alamos has extensive experience in conducting calculations on thermal fuel loads, heat 
removal processes and systems, nuclear criticality considerations, material technology specifications for compatibility, and long-term containment of spent nuclear fuel. Los Alamos has the capability to conduct probabilistic risk assessments to address all technology considerations required to transport, store, and eventually dispose of spent nuclear fuel. By performing consequence analysis associated with risk assessments, Los Alamos would provide recommendations for the design and implementation of transport systems. This would ensure compatibility with an MRS system module and system.

\section{B. Lead in Canisters}

Issue. The DOE has prohibited the use of lead shielding in the multipurpose canister (MPC), classifying it as an unacceptable material for disposal in the repository. It has been stated that the reason for the exclusion of lead from the repository is because lead is a hazardous substance, and its use would cause the MPC and fuel contained therein to be treated as mixed waste (perhaps the basis for this concern stems from reopening the MPC, repackaging of the fuel, and disposal of the MPC subassemblies containing lead). On the other hand, depleted uranium shielding is permitted.

Action. It would be highly desirable, from an economic viewpoint, to use lead shielding in the fuel storage/transportation canisters. The mixed waste argument may be unjustified due to the presence of hazardous and toxic substances in the spent fuel. Therefore, the reasons and cost/benefit justification currently used in the repository requirements to exclude the use of lead in an MPC needs to be validated. The specific technical and regulatory basis for the requirement and a recommended course of action for the storage and transportation system design team are needed.

Benefits. There is a substantial stockpile of lead in the DOE system and in the United States lead bank. This surplus material has no identified application, and disposal will be very expensive. The use of this lead as a shielding material in the storage, transport, and disposal canisters will avoid this disposal cost and reduce the manufactured cost of the canister by at least $10 \%$ when compared with the use of depleted uranium shielding. This would result in a life-cycle cost reduction of at least $\$ 50 \mathrm{M}$.

Los Alamos Response. Lead is a low-cost metal that has historically been used to shield the emission of gamma rays generated by irradiated fuel. Lead is one of several solid metals with a high density $\left(>10 \mathrm{gm} / \mathrm{cm}^{3}\right)$. Other high-density metals, such as hafnium, tantalum, tungsten, 
rhenium, platinum, gold, thallium, and bismuth, are effective in attenuating high-energy $\mathrm{x}$ and gamma-rays from decay of fission products in spent nuclear fuels. Unfortunately, lead is listed as a Resource Conservation \& Recovery Act (RCRA) hazardous metal, and if contaminated with radio nuclides or irradiated by neutrons, it becomes a mixed waste that is difficult and expensive to dispose of after use. The remainder of the high-density elements that are available for attenuation of gamma-rays, based on economic considerations, may be tantalum, tungsten, or bismuth.

Alternatively, depleted uranium has a density of approximately $19 \mathrm{gm} / \mathrm{cm}^{3}$ and is a metal of choice for shielding because of its relative low cost and availability. Encapsulation of lead in such a manner that would eliminate neutron-induced reactions from neutrons emitted by spent nuclear fuel (either from alpha-n reactions, spontaneous fission, or subcritical neutron emissions) would certainly be beneficial for designers of shielded canisters. Alternatively, shielding material made from depleted uranium is a well-known technology. However, encapsulation of metallic uranium components is a complex technology that must be accomplished in a manner that does not allow exposure of the uranium metal to moisture which would corrode the uranium, form reactive uranium hydride, and perhaps form pockets of ignitable hydrogen. Los Alamos has considerable knowledge and experience to recommend the most-effective and economical means of using lead, of determining an alternative to lead, or of using depleted uranium for shielding material.

\section{Filler Materials}

Issue. The DOE plans to utilize burnup credit for geologic repository design. In order to maintain geometry and moderator exclusion for the multipurpose canister (MPC) fuel matrix over long periods of time, the DOE is considering using filler material in the voids within the MPC cavity. The type of material and process for installation in this type of application has not been defined.

Action. In order to ensure compatibility with the repository, it is desirable for the storage and transportation canisters to have the capability for backfilling with filler material. An understanding and review of DOE's plans for this material, such as the characteristics of the material itself, the form in which it will be handled, and the preferred method of canister filling, are needed to incorporate the necessary design features into the storage and transportation canisters. 
Benefits. A better understanding of the repository requirements for filler material and the incorporation of the necessary canister design features will reduce the risk of costly canister modifications.

Los Alamos Response. The filler material for the multipurpose canisters could be a solid metallic, a stable zeolite, or a molecular sieve filler that would satisfy the needs to enhance certain parameters, such as neutron absorption and gamma-ray attenuation. Also, along with gamma-ray attenuation and neutron absorption, a filler to enhance contamination control and eliminate later decontamination requirements could be incorporated into the design of the MPC. Any filler material would have to preclude onset of corrosion, which limits MPC lifetime and results in increased costs.

Los Alamos has the capability to select and justify the addition of an optimized filler for a MPC that would be compatible with the current design of the canister and would result in enhancing the overall effectiveness of the MPC.

\section{Neutron Absorbing Materials}

Issue. There is currently a limited number of commercially available borated neutron absorber materials that are suitable for use in licensed spent fuel storage and transportation packages. These include BORAL TM, which is a composite boron carbide aluminum material and NeutroSorb Plus which is sintered borated stainless steel material. Each of these materials has one or more disadvantages in terms of fabricability, mechanical properties, material aging, $\mathrm{QC}$, and cost. BORAL ${ }^{\mathrm{TM}}$ has excellent boron loading capabilities and is a very effective neutron absorber but has very poor mechanical and thermal aging performance. NeutroSorb Plus has good mechanical and fabricability capabilities but has poor boron loading capability (short of using enriched B10). These materials are expensive (e.g., NeutroSorb Plus costs in the range of $\$ 10$ to $\$ 15$ per pound) and substantially impact the overall cost of the MPC internal basket.

Action. It would be ideal to utilize a poison material for spent fuel package criticality control (without using credit for burnup) that has the neutron absorber capabilities of BORALTM; the mechanical, aging, and fabricability capabilities of NeutroSorb Plus; and a low cost. Other materials that need to be evaluated for their applicability include borated aluminum, cadmium sheets, and lithium hydride (in a suitable form). Another option would be to use borated stainless steel with enriched B10, but the cost of this material has historically been on the order of more than $\$ 100$ per pound (e.g., NeutroSorb Plus with enriched B10). It should be 
determined if there is a source of enriched B10 in the DOE system that could be obtained at substantially reduced costs. The result of this investigation should be a matrix of materials, the microscopic cross-section of the product (barns per cubic centimeter), the thickness required to provide the same neutron absorption as a given thickness of a BORALTM sheet, and the corresponding cost per unit area. In addition, the result should give the mechanical properties of the finished product, including the yield strength, tensile strength, and elastic modulus at both 70 degrees Fahrenheit and 500 degrees Fahrenheit and the Charpy impact strength at -20 degrees Fahrenheit.

Benefits. Current neutron absorbing materials represent about $25 \%$ of the manufactured cost of a storage and transport canister. Currently, the only way to limit the use of these expensive materials is to utilize burnup credit, which, to date, has not been approved by the NRC. Also, the DOE may have stockpiles of the constituent materials, e.g., boron carbide, enriched B10, aluminum, and stainless steel, which currently have no application and which could be used for the development of a more-effective neutron absorbing material. Assuming that such an improved material is half the cost of current materials, life-cycle costs would be reduced by at least \$70M.

Los Alamos Response. Staff members in the Material Science and Technology Division, working with experts in the Nuclear Design and Safety Groups, could recommend the most effective and economical material for absorbing neutrons. There are inventories of boron enriched in B10 that could be pursued and borated metal composites that could be developed. Boron carbide as well as boron nitride have been extensively used in nuclear reactor systems. Los Alamos has conducted extensive tests on these and other boron-rich materials and has the capability to establish the physical characteristics that are most important in fabricating effective neutron absorber materials. Also, the availability of rare-earth elements (from Chinese sources) with the highest thermal neutron absorption cross-sections has increased significantly, and composites of these materials could be incorporated into the design of fuel storage and transportation packages. The thermal neutron absorption cross-section of gadolinium is $\sim 50,000$ barns relative to boron with 760 barns or enriched B10 with $\sim 4,000$ barns.

\section{Neutron Shielding Materials}

Issue. There are currently a number of hydrogenous neutron shielding materials that are suitable for use in spent fuel transportation casks. One of these materials is BISCo NS-3 
(formerly owned by BISCo and now owned by Genden Engineering Services and Construction Co. (GESC) of Japan; the US licensee is NAC Services, Inc.), which is a cementicious material having sufficient hydrogen content, a high weight density, low thermal conductivity, and a low thermal expansion coefficient. Others are Boro-Silicon and BISCo NS-1, both of which are polyfoam materials having superior hydrogen content, a low weight density, low thermal conductivity, and a high thermal expansion coefficient. These materials typically encapsulate the cask to provide biological shielding and, as a result, substantially limit the heat removal capacity of the cask. These materials also off-gas hydrogen in the form of water vapor at temperatures exceeding 250 degrees Fahrenheit. Adequate material qualification testing and $\mathrm{QC}$ is also a problem with these materials.

Action. It would be highly desirable to utilize in the transportation cask a neutron shielding material for the transportation cask which has high hydrogen content, low weight density, increased thermal conductivity, low thermal expansion, and does not degrade at temperatures less than $\mathbf{3 5 0}$ degrees Fahrenheit. It should be determined if there is a neutron shielding material that is either commercially available (perhaps in an unrelated application) or could be developed or enhanced for use in a shipping cask design. It should also be determined if there is a composite material that could provide both effective neutron shielding and gamma shielding performance.

Benefits. The performance of many transportation packages and their ability to accommodate extended burnup fuel is limited by the existing neutron absorber materials utilized in transport cask designs. This limitation results in a reduced canister payload, which substantially increases fuel shipments, resulting in higher life-cycle costs and increased public risk.

Los Alamos Response. (See discussion on neutron absorbing materials.)

\section{Alternate Gamma Shielding Materials}

Issue . Existing large transportation casks use steel or lead as the gamma shielding material. However, for large casks it is often desirable to minimize the weight by minimizing the thickness of the gamma shield, thus maximizing cask payload. Depleted uranium has been used in smaller casks, such as the GA 4/9 truck cask and the 75-ton IF-300 rail cask. It is more difficult to use depleted uranium in large casks as industry casting-size capabilities are limited. The available methods for fabrication and assembly of depleted uranium have generally been derived from process technologies developed in weapons programs, both 
nuclear and kinetic. Frequently, the only available manufacturing facilities have been those engaged in these programs. This results in a dilemma for the cask designer since the selection of the particular design features for the cask are dependent on access to the manufacturing capabilities for this material. As a result, it is desirable to investigate alternative materials or to develop more practical manufacturing processes for use of depleted uranium in transport casks and canisters. Also, there currently does not appear to be a way for private industry to procure this material from the DOE even though the agency has large quantities of this material that has no current application.

Action. It should be determined whether other high-density materials that are cost effective and manufacturable are suitable for use in a large transportation rail cask. The diameter of the gamma shield will be on the order of 67 inches. The goal is to identify a material that has a high density and can be cast in large enough sized rings. Also, the finished cost should be compared with that of depleted uranium, and ways to improve the current process for the manufacture and assembly of depleted uranium subassemblies should be investigated. An interactive dialog should be established with current facility experts to develop the methodology for the design and manufacture of, for example, machined stepped rings, laminated sheets, and composite depleted uranium/lead constructions. Establish a means of procurement for this material from the DOE.

Benefits. The use of casks with reduced wall thickness and increased payloads achieved through the use of high-performance gamma shielding materials will reduce the number of shipments required and reduce the resulting life cost.

Los Alamos Response. (See discussion on lead in canisters) This is one area in which the Materials Science and Technology Division could provide detailed support in the design, fabrication, and implementation of highly effective materials for radiation shielding.

\section{Prevention/Minimization of Concrete Activation}

Issue. During storage of canisterized spent fuel in a concrete overpack, the inner inch or two of the concrete may become activated to a level that requires disposal as radwaste. This requires that the whole overpack unit be sent to a disposal site for burial, which will be very expensive because of its large size. Alternatively, the inner surface of the concrete can be chipped out for disposal, which reduces the amount of waste to be buried but has costs associated with the chipping and control of the fines and dust. It is desirable to mitigate the 
activation of the inner concrete surface of the overpack to levels that will permit it to be disposed of as standard landfill.

Action. Studies or experimentation should be performed to determine the extent to which concrete may become activated for an exposure range of concrete aggregate constituent materials and a range of neutron source terms and durations. The time required for activated concrete to decay to free release levels once the source is removed should be determined. The possibility of using an economical readily disposable neutron absorber materials, such as a polysheet material to line the inner surface of the concrete overpack, should be investigated. The characteristics of such materials and the required thickness of material should be determined. A 40-year storage life for the overpack and 24 spent fuel assemblies ( $3.3 \mathrm{w} / \mathrm{o}$ enriched, 40,000 MWd/MTU burnup, 5-year cooled) in a 1" thick canister should be assumed.

Benefits. Disposal of activated concrete is currently the single biggest driver in the cost for decommissioning of dry fuel storage facilitates. Means to mitigate the activation levels of the concrete overpacks would substantially reduce the cost of decommissioning such a facility and would remove an indeterminate financial risk from the life-cycle cost.

Los Alamos Response. Los Alamos has conducted studies on the use of high neutron absorber materials to prevent/minimize concrete activation. The design of the proposed Los Alamos MRS module includes neutron absorbers to prevent/minimize activation of concrete. Los Alamos has the facilities to conduct studies on the neutron fluence that the concrete would experience over the lifetime of the overpack and can provide calculations that would quantify the activation that would result for different neutron fluxes over a 40-year storage life. Los Alamos has the expertise to establish the shape, geometry, and quantity of the neutron absorber material needed to ensure nonactivation of concrete over the 40 -year storage period. 


\section{Appendix B. Application of Inert Gas Analysis for Detecting and Monitoring the Integrity of Spent Fuel.}

The design of the proposed MRS test module outlined in this report would allow for monitoring of the integrity of both the primary and secondary containment systems used to store the spent fuel. Monitoring will be accomplished either by analyzing the stable inert fission gases that are generated during the irradiation process in a nuclear reactor or by analyzing the spiked natural isotopic blends of stable inert gases. The use of xenon (Xe) and krypton (Kr) gas tags for identification of fission gas release from the primary containment cladding of nuclear fuel has been demonstrated at the Experimental Breeder Reactor III Facility at Argonne National Laboratory. A similar technology has been investigated at Los Alamos National Laboratory. In addition, researchers at Los Alamos are currently studying the analysis of an expanded suite of inert gas tags that can be used to detect and identify failed fuel elements in a nuclear reactor. For example, a breach in the primary cladding material can be identified by periodically using a specialized mass spectrometer or quadrupole mass spectrometer to analyze the reactor head space volume of $\mathrm{Kr}^{85}$ (half-life of 10.76 years) or stable xenon or krypton fission gas isotopes.

Analytical techniques to monitor the stability of secondary containment systems used in the experimental MRS module would include inert gas added to the atmosphere of the spent fuel containment vessel. Once the secondary containment vessel is sealed, an automated system would sample and analyze the gases in the storage system to determine the presence of inert gases which would indicate a breach in the secondary containment system. Existing analytical instrumentation has the capability to analyze inert gases (i.e., neon, argon, krypton, and xenon) in the parts-per-billion range without the need to separate or concentrate the sample gas mixture. The addition of helium to the MRS containment system would be used to determine the integrity of the system within the atmosphere of the MRS module.

Currently, helium is added to storage and transportation casks to provide an inert atmosphere for the spent fuel to minimize corrosion and to offer an additional safety factor to prevent fires or explosions.

These enhancements, along with technology to analyze inert gases, would allow monitoring of the integrity of spent fuel cladding, the storage facility, and waste containers for many decades. Analyses of $\mathrm{Xe}$ and $\mathrm{Kr}$ isotopes and incorporation of measurement of isotopic ratios will allow direct determination of burnup on nonclad fuel. Clad fuel burnup can be established by laser puncturing the fuel plenum, measuring the fission gas isotopic ratios, and finally rewelding the punctured hole by defocusing the laser on the area around 
the hole. This technology is available at Los Alamos and could be applied to spent fuel that will be stored in total containment modules. 


\section{Appendix C. Factors for the Assessment of Technology Development for MRS Projects.}

Technical Maturity. This factor addresses the readiness of an MRS design to be incorporated into a storage facility, without requirements for additional developments. Key elements include storage demonstration scaled sequentially through bench, pilot, and full storage demonstrations. Additionally, this includes where the storage design and demonstration is performed, whether it can be readily engineered, and what risk is involved in delivering a functional system.

Flexibility. This factor addresses the ease by which a storage process can meet changing requirements, including those which are currently unknown, and how that flexibility will be integrated into the facility design.

Complexity. This criteria encompasses the difficulty in storage maintenance, control, and level of operator expertise needed to execute the process. This can be defined as the number of unknowns in the facility design that indicate the level of understanding of the basic concepts and the execution of the steps required to achieve the desired end product.

Health and Safety. This issue can be subdivided into industrial safety and radiation safety. Industrial safety will influence engineering practices and risk; radiation safety will affect design to minimize personnel radiation exposure.

Safeguards and Security. This factor addresses the criteria by which the design and construction of the facility can inherently provide material control and accountability. These criteria include physical barriers, nuclear materials assay for accountability, and computerized nuclear materials inventory control. 